\title{
Participatory Action Research Methodology in Disaster Research: Results From the World Trade Center Evacuation Study
}

\author{
Robyn R.M. Gershon, MHS, DrPH, Marcie S. Rubin, MPH, MPA, \\ Kristine A. Qureshi, DNSc, Allison N. Canton, BA, and Frederick J. Matzner, MD
}

\section{ABSTRACT}

Objective: Participatory action research (PAR) methodology is an effective tool in identifying and implementing risk-reduction interventions. It has been used extensively in occupational health research, but not, to our knowledge, in disaster research. A PAR framework was incorporated into the World Trade Center evacuation study, which was designed to identify the individual, organizational, and structural (environmental) factors that affected evacuation from the World Trade Center Towers 1 and 2 on September 11, 2001. PAR teams-comprising World Trade Center evacuees, study investigators, and expert consultants-worked collaboratively to develop a set of recommendations designed to facilitate evacuation from high-rise office buildings and reduce risk of injury among evacuees.

Methods: Two PAR teams worked first separately and then collectively to identify data-driven strategies for improvement of high-rise building evacuation.

Results: The teams identified interventions targeting individual, organizational, and structural (environmental) barriers to safe and rapid evacuation.

Conclusions: PAR teams were effective in identifying numerous feasible and cost-effective strategies for improvement of high-rise emergency preparedness and evacuation. This approach may have utility in other workplace disaster prevention planning and response programs. (Disaster Med Public Health Preparedness. 2008;2:142-149)

Key Words: evacuation, participatory action research teams, high-rise buildings, workplace

$\mathrm{T}$ The World Trade Center (WTC) evacuation study was designed to identify the individual, organizational, and structural (environmental) factors that affected evacuation from WTC Towers 1 and 2 on September 11, 2001. This project used an ecological participatory action research (PAR) framework throughout all phases of the study. ${ }^{1}$ From the inception of the project, and in keeping with published recommendations for the ethical conduct of disaster research, ${ }^{2,3}$ WTC evacuees and other key stakeholders were involved in formulating the study questionnaire, data collection procedures, and feedback and dissemination plan. ${ }^{3}$ At the conclusion of the data analysis phase, PAR teams were formed. These comprised WTC disaster evacuees, study investigators, and consultants with a wide range of expertise, including fire safety, disaster mental health, emergency planning, occupational safety, and high-rise building management. Over several months, the team members worked together to identify strategies to improve emergency preparedness processes and procedures for high-rise building evacuation. The final recommendations developed by the PAR teams were presented at 2 conferences, one de- signed for the lay community, including the general public and WTC disaster survivors, and another for the scientific community, including fire safety, emergency preparedness, and disaster researchers and practitioners. This article reports on the utility of the PAR process as an emergency preparedness methodology and presents the PAR team recommendations for improvements in high-rise building evacuation.

\section{PARTICIPATORY ACTION RESEARCH}

Sixty years after Kurt Lewin proposed the concept of action research, this framework has evolved to encompass a range of applied research methodologies that promote change and empowerment at the group, organizational, and societal levels. ${ }^{4,5}$ Included under the umbrella of action research, PAR is an approach to research in which professional researchers actively engage and collaborate with members of the study population on all phases of the project (from the study design to the presentation of results and discussion of implications). ${ }^{6,7}$ As discussed by Baker, Israel, Greenwood, and others, action research is guided by a number of foundational principles. ${ }^{8-10}$ These include ${ }^{11}$ performing research that: 
1. Is participatory (ie, study participants are involved in all phases)

2. Is collaborative (ie, researchers, consultants, and study participants contribute their expertise and, to the extent possible, share decision making and control of the research process)

3. Fosters co-learning (ie, skills and knowledge are exchanged in a reciprocal manner between all of the parties, with special emphasis given to the expertise that study participants have regarding their personal experiences, their organization, or their community)

4. Involves system development (ie, the system or group uses the competencies of each party to engage in the multistage research process)

5. Is empowering (ie, all partners gain influence and control through their participation)

6. Balances knowledge generation and intervention development (ie, strikes a balance between generating knowledge and developing interventions or policies for the mutual benefit of all parties)

The utility and effectiveness of PAR methodology has been particularly promising in the field of occupational safety and health. Because PAR involves an empowering process that emphasizes collaboration and colearning among workers and researchers, ${ }^{12}$ it promotes knowledge generation and systemslevel improvements in organizational and occupational settings. ${ }^{13}$ This approach has been useful for identifying and implementing risk management strategies in the workplace, including those aimed at reducing occupational stress and enhancing employee well-being. 10,11,13-15 PAR methodology has been demonstrated to be particularly effective in worksite health promotion because it creates a climate for building trust among researcher, labor, and management participants, and often provides researchers with first-hand insights. ${ }^{13-15}$ It is important to note that PAR recommendations are more likely to be acceptable to all stakeholders when stakeholder representatives are involved in the process.

Within occupational research, the PAR process is especially well suited to workplace disaster research and the identification of risk reduction interventions. First, because PAR team members are survivors of a workplace disaster, the opportunity to learn from their firsthand experiences is invaluable. Second, by having professional researchers, members of the study population, and expert consultants participate and collaborate in a colearning process, the team is likely to generate recommendations that are innovative, relevant, and practical. Third, participation in the PAR process may be both psychologically beneficial and empowering for disaster survivors. ${ }^{16-18}$ For example, trauma and disaster researchers have found that discussing a traumatic experience in a safe and supportive manner can be healing. ${ }^{3,16-19}$ Also, the group nature of the PAR teams allows participants to network with other survivors and to develop an additional source of social support. Furthermore, it may feel inspiring or uplifting for disaster survivors to be able to contribute to scientific knowledge that may be potentially lifesaving for others. For all of these reasons, embedding PAR in disaster research is a reasonable approach for identifying risk-reduction strategies.

\section{METHODS}

\section{World Trade Center Evacuation Study}

The WTC evacuation study was a 3-year, 5-phase multidisciplinary and collaborative study ${ }^{1}$ (Fig. 1) designed to identify factors that affected the length of time to initiate and

FIGURE 1

World Trade Center evacuation study overview. Reprinted with permission from Prehospital and Disaster Medicine.

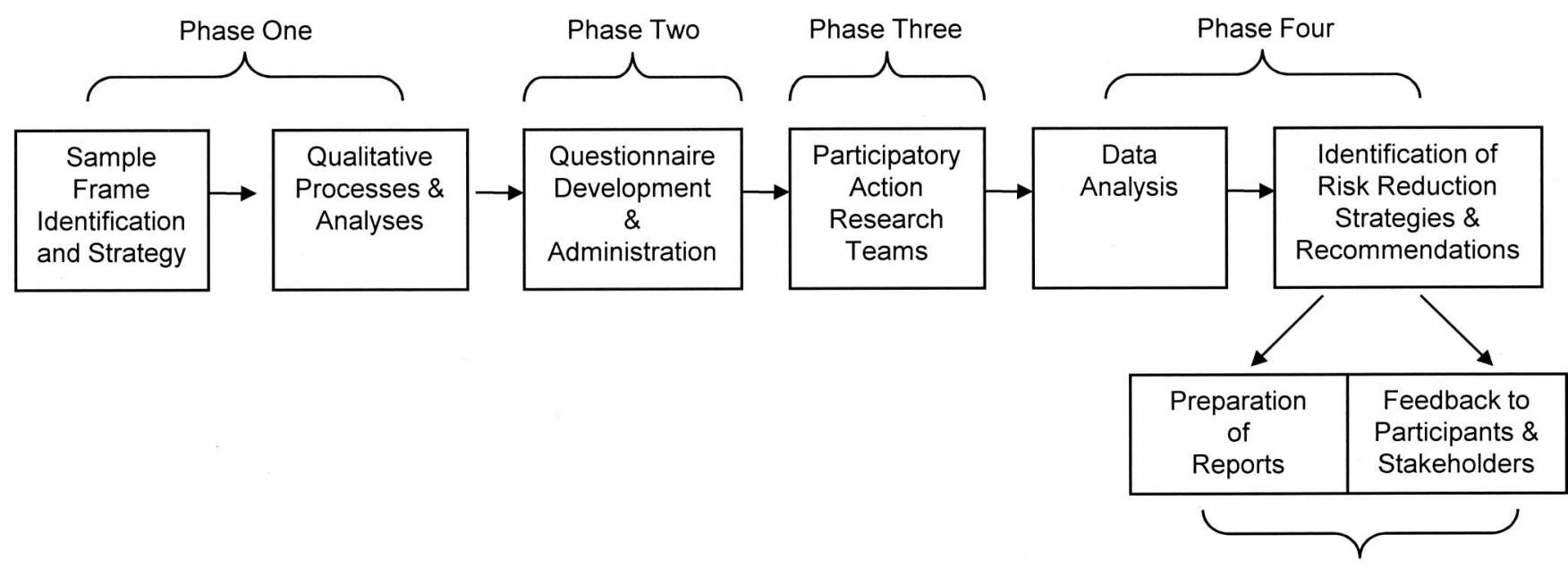

Phase Five 
complete evacuation from WTC Towers 1 and 2 on September 11, 2001, controlling for a number of variables such as use of elevators, as well as risk factors for sustaining injury during the evacuation process. By identifying and better understanding these factors, the study aimed to inform improvements in high-rise building design, codes, standards, and evacuation procedures to reduce or minimize the risk of harm in the event of other extreme high-rise emergencies. Data were collected using both quantitative and qualitative procedures, including key informant interviews, in-depth interviews, focus groups, and the administration of a 95-item questionnaire, which could be completed either online or by mail.

Participants for both qualitative and quantitative phases were recruited from 2 major sources: a large, random sample of WTC employees and contractors selected from a security badge list, and the New York City Department of Health and Mental Hygiene WTC Health Registry. ${ }^{20}$ A total of 1767 people who worked in WTC 1 or 2 at the time of the September 11, 2001, terrorist attacks completed the study questionnaire; of these, 1444 actually evacuated the building on September 11, 2001. Team members were recruited from this evacuee population. The demographics of the PAR team members were similar to the WTC evacuees who completed the study survey. Data from both the questionnaires and qualitative procedures were analyzed and summarized and information from the evacuees was prepared for nonscientists using a number of total quality management techniques, such as Pareto charts, fishbone diagrams, and flowcharts. ${ }^{21}$

\section{PAR Teams}

In addition to the evacuees recruited, professional study investigators and experts from a wide range of specialties who had served on the study advisory board or were involved with earlier phases of the study were also members or invited guests of the PAR teams. Each of 2 PAR teams consisted of 5 and 6 study population members, respectively (45\% male, 91\% white), roughly half from Tower 1 and half from Tower 2. Members evacuated from as low as the 10th floor (Tower 1) and as high as the 97th floor (Tower 2). The teams met with at least 3 professional researchers and consultants, met for 3 hours once per week for 3 consecutive weeks, and then monthly for 12 months. Members were selected in 1 of 2 ways; first, roughly half responded to recruitment to earlier study procedures (eg, focus groups) and were not able to attend those research activities because of scheduling conflicts. The names of those interested in future activities were added to a list of potential PAR team participants and contacted when the teams were formed. Second, participants completing the survey could check a box indicating their interest in being contacted in the future, and a random sample of these individuals was contacted. None of the members had ever met before the formation of the team.

The teams were organized and managed following standard procedures and processes. ${ }^{21}$ (Contact corresponding author for assessment details and copies of research materials.) During the first meeting, team building exercises were conducted and the mission, goals, and objectives of the team were established. During the second meeting, the findings of the WTC evacuation study were presented using total quality management techniques designed to explain data to nonscientists (eg, Pareto charts, flow diagrams, fishbone diagrams) and participants began to engage with the data. In the third meeting, the teams started to develop data-driven recommendations for improvement based on the findings and informed by personal experience. Input also was considered from experts representing a wide range of expertise, including fire safety, elevator safety, urban infrastructure, emergency planning, disaster mental health, and disability advocates. More than 30 nationally acclaimed experts collaborated on the WTC evacuation study at some point in time. Twelve of these experts met with the PAR teams at least once. Experts provided their perspectives and understanding of the data and considered some of the team's ideas and then provided feedback. The experts were interested in the validation of the data that the team members provided. After this initial series of meetings, 6 subsequent bimonthly PAR team meetings were conducted with the combined membership from both PAR teams. The combined meetings enabled participants from each group to consider the other group's findings and to jointly refine the final recommendations. At the end of each meeting, team members provided anonymous written evaluations to give feedback on the process and experience in a timely manner.

All procedures involving human subjects, including PAR team procedures, had prior review and approval of the Columbia University Institutional Review Board, and signed informed consent was obtained from each participant before the first session. To protect potentially vulnerable disaster research participants, measures were taken to ensure the decisional capacity of PAR team members, as described in a recently published paper. ${ }^{3}$ These measures included prescreening participants in a telephone interview to assess decisional capability (eg, posttraumatic stress disorder symptom screening, demographics, mental health and prescription history) to determine their eligibility to participate as well as the potential for adverse psychological effects resulting from their participation in the study. In addition, as a further protection, the study's trauma psychiatrist attended at least 1 of the sessions of each group. This allowed the team members to become familiar with the psychiatrist, who remained on call for emergencies or consultation for the duration of the teams' processes. The study aimed to inform improvements in high-rise building design, codes, standards, and evacuation procedures to reduce or minimize the risk for harm.

\section{RESULTS}

The PAR teams first identified key risk factors associated with 3 major outcomes (length of time to initiate evacuation, length of time to complete full evacuation, and incidence of injury). All of the data prepared for the teams controlled for originating floor and use of elevators. The PAR teams identified 83 recommendations that addressed risk factors associated with the 3 major outcomes. 
Most (42; 51\%) of the recommendations were aimed at the organizational level, 22 (26\%) were at the structural level, and $19(23 \%)$ were at the individual level. Of the 83 total recommendations, 33 (40\%) focused on initiation delays (Table 1), 35 $(42 \%)$ on length of time to fully evacuate (Table 2), and 15 $(18 \%)$ on risk for injury (Table 3 ).

With respect to factors that delayed initiation of evacuation (Table 1), organizational level (ie, employer or building management) and individual level (ie, employee) factors were the most frequently cited (42\% and 33\%, respectively). Organizational level factors were most often cited $(63 \%)$ as risk factors that increased the length of evacuation time (Table 2), although $31 \%$ of the recommendations were at the structural level (ie, building design and features). Individual level factors and organizational factors were equally attributed for the majority of risk factors associated with sustaining an injury (40\% in each category; Table 3). Several of the key recommendations for each of the 3 outcomes are described below.

\section{Recommendations to Address Delays in Initiation of Evacuation}

Because initiation delays were related, to a large degree, to "milling about" behaviors (eg, seeking out others to obtain information,

\section{TABLE 1}

\section{Summary of Participatory Action Research (PAR) Team Recommendations: Risk Factors That Delayed Initiation of Evacuation}

\section{Risk Factor}

1. Seeking out others to form a group for mutual support and information-sharing during evacuation

2. Personal concerns about own health and ability to evacuate

3. Individual behaviors that delayed initiation of evacuation (eg, gathering items, making telephone calls, work-related tasks, waiting for directions or permission to leave, changing shoes)

4. Uncertainty about which evacuation route to take including: exit locations, staircase endpoints, roof access, locked reentry points, when to use elevators

\section{Recommendations for Improvement by Category}

- Participate in group activities both within company and on the floor where office is located (I)*

- Be prepared to act based upon instinct and "gut feelings" if complete information or guidance from leadership is unavailable (I)

- Have multiple sources of communication available (eg, battery operated radio) (I)

- Share information about unusual circumstances with coworkers as soon as they occur (I)

- Support preevent group formation with programs such as workplace coffee hour, ongoing social activities across floors and among floors $(0)^{*}$

- Management/employer should provide accurate information early in the event to employees $(0)$

- Provide clear, consistent, and accurate messages (0)

- Provide wireless cellular telephones for the safety team members $(0)^{*}$

- Link company computers to television stations, emergency broadcast announcements (eg, NYC Office of Emergency Management) (O)

- Limit nonemergency public address (PA) announcements to only those that are necessary $(0)^{*}$

- Use multiple environmental cues (eg, flickering lights) to alert occupants of an unusual occurrence (S)*

- Install backup communication systems (S)

- Equip buildings to allow for emergency radio broadcast announcements (S)

- Equip elevators and staircases with systems for public announcements (S)

- Link all communication sources to 1 main broadcast site (S)

- Individuals should conduct self-assessment of their capability and time needed to fully evacuate (I)

- Individuals should inform the building's safety personnel of any special evacuation needs (I)

- Institute system to rapidly identify those who will require special assistance for evacuation $(0)^{*}$

- Preplan for people with disabilities (O)

- Perform evacuation drills for people with special evacuation needs, including situations in which elevator does not function (O)

- Maintain an emergency "go bag" at desk (I)

- Delay calls until completely exited (I)

- Take ownership of personal safety actions (ie, act independently) (I)

- Wear sensible footwear that will facilitate rapid evacuation (I)

- Maintain evacuation supplies by the exits that are not locked and are easily accessible $(0)^{*}$

- Implement policies that support employee initiative for evacuation (0)

- Install emergency supply storage receptacles near exits (S)*

- Compliance with training and drills (I)

- Facilitate a workplace climate for emergency preparedness (O)

- Enforce training and education of all employees for evacuation (O)

- Enforce mandatory drills that involve entry into the staircase and various routes for terminal egress $(0)$

- Color code the exit doors so that their location (eg, N, S, E, W) is clear to help orient employees $(\mathrm{S})^{*}$

- Post signage that indicates where staircases terminate $(S)^{\star}$

I, individual level; O, organizational level; S, structural level.

* Recommendations that were clearly identified by PAR team members.

Table reprinted with permission from Burke R, Cooper CL, eds. International Terrorism and Threats to Security: Managerial and Organizational Challenges. Cheltenham: Edward Elgar; 2008. 


\section{TABLE 2}

Summary of Participatory Action Research (PAR) Team Recommendations: Risk Factors That Increased Length of Time of Evacuation

\section{Risk Factors}

1. Lack of knowledge and poor emergency preparedness of workers

2. Footwear that inhibited rapid exit down stairs and through lobby debris field

3. Staircase characteristics (eg, width, design, access)

4. Complex building design caused confusion

5. Poor or missing signage

6. Suboptimal workplace emergency safety climate

7. Inadequate communication system infrastructure

8. Transportation of responder supplies

9. Flow of traffic in certain areas led to congestion on stairs

10. Procedures for evacuation of people with health conditions or disabilities (PWHC/D)

\section{Recommendations for Improvement by Category}

- Active participation in training and drills (I)

- Conduct training and drills (O)

- Incorporate entry into stairwells in fire drills (O)

- Promote an organizational emergency preparedness safety culture/climate from top down (O)

- Conduct specialized safety training for senior management $(0)$

- Foster employer ownership of safety training and climate, accountability enforced by building owner (O)

- Garner political and regulatory support for training and drills $(0)$

- Clarify use of elevator vs stairs during emergencies (O)

- Encourage wearing sturdy, closed-toe, flat-soled footwear in the workplace (I)

- Widen staircases when feasible (S)

- Consider drainage for water on stairs $(\mathrm{S})^{*}$

- Assign widest staircases for evacuation and accommodation of people using wheelchairs (S)

- Ensure that doors to floors off stairwells unlock during emergency (S)

- Design high-rise buildings that are intuitive and easy to navigate (S)

- Improve signage (S)

- Ensure an organizational safety culture including emergency preparedness from top down (O)

- Conduct specialized emergency preparedness safety training for senior management (O)

- Foster employer ownership of safety training and climate, with accountability to be enforced by the building owner $(\mathrm{O})$

- Ensure a working emergency generator and public announcement system (S)

- Link buildings to television station and personal computers for better communication (S)*

- Place emergency supplies throughout the building $(S)^{*}$

- Assess building capabilities to support evacuation (S)

- Stagger evacuation of occupants to reduce numbers of people on stairs $(0)^{*}$

- Designate specific staircases for slow movers or those that need special assistance (0)

- Practice use of evacuation chairs by coworkers or response team (0)

- Preparedness planning for PWHC/D (O)

- Code identification badges to permit rapid identification of PWHC/D (O)*

- Instruct PWHC/D to use elevators if/when directed by safety personnel (O)

- Assign "buddies" for evacuation of PWHC/D (O)*

- Train those assisting PWHC/D on how to handle cases in which carrying is necessary $(0)^{*}$

- Pass new regulations to protect PWHC/D (O)*

- Ensure confidentially of information about PWHC/D (O)

- Perform special evacuation training/drills for PWHC/D (O)

- Keep extra wheelchairs on lobby level for PWHC/D $(0)^{*}$

- Designate widest stairwell for PWHC/D (S)

I, individual level; O, organizational level; S, structural level.

${ }^{*}$ Recommendations that were clearly identified by PAR team members.

Table reprinted with permission from Burke R, Cooper CL, eds. International Terrorism and Threats to Security: Managerial and Organizational Challenges. Cheltenham: Edward Elgar; 2008.

looking for leadership), most of the recommendations aimed at this outcome focused on ways to communicate important information in a high-rise building, both with and without the use of the existing communication infrastructure. Because not all high-rises have public address systems and because these systems are vulnerable to power outages, the teams suggested the backup and redundant systems using battery-operated equipment. In general, the teams recommended that a single coherent, accurate, real-time message be frequently broadcast over as many systems (eg, public address system, radio, computer networks, television, personal digital assistants) as possible so that information about the event could be diffused rapidly and widely. Updated information should be broadcast frequently as well. This information, along with managers encouraging employees to quickly start evacuation, was seen by PAR team members as important in empowering employees to act on their own in the absence of leadership from a supervisor or emergency personnel.

To assist groups in forming rapidly, the teams recommended that high-rise buildings support social functions on each floor (in large high-rises there may be multiple tenants, and thus multiple employers, per floor), so that occupants can become familiar and feel socially connected with one another, which in turn may help groups form more rapidly. 
A B

Summary of Participatory Action Research (PAR) Team Recommendations: Risk Factors Associated With Sustaining an Injury

\section{Risk Factor}

1. Weak emergency preparedness

2. Stair/building environment

3. Health condition or disability of evacuees

4. Footwear

\section{Recommendations for Improvement by Category}

- Support and encourage individuals to have a positive safety attitude (I)*

- Participate in training drills (I)

- Promote a strong organizational safety culture/climate (0)

- Designate use of the widest staircase for people with disabilities or the injured (0)

- Develop innovative methods for evacuation (O)

- Issue flashlights to occupants (O)

- Widen existing stairs (S)

- Maintain evacuation supplies throughout the buildings $(\mathrm{S})^{*}$

- Reduce possibility of broken glass in the environment (S)

- Awareness of people with health conditions or disabilities in the individual's work area (I)*

- Conduct self-assessment of capabilities (I)

- Awareness of all occupants regarding location and use of safety equipment (I)*

- Promote organizational commitment for a disability emergency preparedness climate $(0)$

- Seek out and provide specialized training for volunteer assistants (O)

- Educate building occupants regarding use of sensible shoes that will support rapid evacuation (I)

I, individual level; O, organizational level; S, structural level.

*Recommendations that were clearly identified by PAR team members.

Table reprinted with permission from Burke R, Cooper CL, eds. International Terrorism and Threats to Security: Managerial and Organizational Challenges.

Cheltenham: Edward Elgar; 2008.

Many people delayed their initiation in the WTC evacuation because of their concerns regarding their physical ability to evacuate using the stairs. In particular, older individuals and people with disabilities or preexisting medical conditions delayed their initiation of the evacuation process, and the teams believed that the best way to address this was through careful preplanning by the potentially affected employee in close consultation with the employer and/or building management (fire safety team). The teams strongly believed that it was the individual's responsibility to inform building management and/or his or her employer. The building or the employer would then be responsible for maintaining this information in a confidential manner and for developing a safe plan for the evacuation of these individuals.

The teams recommended many simple steps that employees could take to shorten the time from awareness of an event to actually beginning their evacuation. These included wearing (or having readily available) comfortable footwear and having emergency supplies, such as water bottles and flashlights, conveniently located adjacent to stairwells.

One of the most important recommendations the teams made was to encourage the development of a strong emergency preparedness climate-employees' collective perception of management's commitment to emergency preparedness. The teams recognized the existence of cultural (ie, safety culture) differences between work organizations with respect to preparedness. They also recognized the critical role of senior leadership in developing a strong emergency preparedness climate and in communicating this to personnel.

\section{Recommendations to Address Length of Time to Fully Evacuate}

Individuals who descended slower than the average length of time (controlling for originating floor and use of elevator) tended to do so either because of physical limitations (ie, preexisting medical conditions or preexisting disabilities) or because of injuries incurred during the attack, which resulted in both a slower pace and/or frequent rest stops. To address this, the teams recommended targeting organizational preparedness so that these individuals could be appropriately and rapidly assisted. Many of these recommendations highlighted training. A number of recommendations to help speed evacuation also targeted structural aspects of high-rises (eg, wider staircases, if feasible, improved signage). Other recommendations targeted the management of the building's structure. For example, the teams recommended that 1 staircase be designated for use by slow-moving individuals and/or emergency responders.

\section{Recommendations to Reduce Risk for Injury}

Most of the serious injuries that were sustained in the WTC attack occurred in the immediate aftermath of the planes' impacts; people who were in the areas located near the point of impact were most likely to be injured. However, many people, mostly women, sustained cuts to their feet when they discarded their shoes because of discomfort and then encountered glass at the lower levels. In some cases, the foot injuries inhibited their ability to walk, causing them to rely on others to help them fully egress the buildings and leave the immediate vicinity of the towers. Once more, the teams strongly recommended comfortable footwear-either wearing it or having it immediately available to all high-rise occupants. Another group of individuals who frequently sustained injuries were those with preexisting disabilities or medical conditions. This is probably because the 
longer it took to evacuate, the greater the chance for injuries, because the physical condition of the building became increasingly compromised. Again, the teams recommended targeted preparedness for people with disabilities, with joint responsibility shared between the disabled person and the organization and/or the building manager.

\section{DISCUSSION}

It is interesting to note that the teams frequently recommended the development of new regulations or the strict enforcement of existing regulations to support the implementation of their recommendations. They strongly supported mandatory training and drills, including full-building evacuation drills. The responsibility for preparedness was placed, for the most part, equally on the building management and the employer-in other words, a shared responsibility. The team urged cooperation between the 2 entities to ensure adequate preparedness; however, individual responsibility also was acknowledged. To promote the safety and welfare of all, team members thought that high-rise occupants had a responsibility to themselves and others, including first responders, to respond quickly and appropriately. Attending, paying attention to, and actively participating in safety training, including emergency evacuation training, was seen as a mandatory obligation of all occupants. One of the most important recommendations the team made was to encourage the development of a strong emergency preparedness climate.

Many of the recommendations made by the PAR teams would be relatively simple to implement by high-rise building management, often at no or low cost (except, of course, the cost of personnel hours spent in training). The recent New York City codes affecting high-rise safety ( 3 RCNY \$6-02; 3 RCNY §9-08) actually require many of the recommendations that were made by the teams. ${ }^{22,23}$ Although the legislation itself predated the PAR teams' work, in 2006-2007 the researchers were able to provide extensive information from the teams to the New York City Fire Department leadership involved in making the new codes operational. This legislation, which addresses requirements for high-rise commercial buildings, including the designation and training of an emergency action plan director, has been extremely well received by all stakeholders. To date, 1236 high-rise fire safety directors have been certified as emergency action plan directors, and each director's building has been or will be scheduled for on-site inspection (S. Ertrachter, personal communication (written), March 14, 2008). These new laws resulted in significant changes in how New York City high-rise business occupancies prepare for all types of emergencies that may affect building occupants, ranging in response from in-building relocation to full-building evacuation. Many other states are adopting similar regulations to address high-rise safety during emergencies.

\section{CONCLUSIONS}

The implementation of PAR teams to identify emergency preparedness and response strategies is a valuable approach for innovative quality improvement. A review of the 83 PAR recommendation identified that at least 20\% were novel. Even though the researchers had analyzed and reviewed both the qualitative and quantitative data, and were well acquainted with the high-rise safety literature, the PAR teams still identified new and innovative recommendations. PAR teams are also costeffective; depending on the number of teams that are formed, expenses are relatively minimal. The experience and insights of the team members provide a unique perspective for identifying practical ideas. More important, the PAR teams also were able to validate the recommendations that the research team made based upon the survey data. Most of the teams' recommendations can be implemented easily, often at low cost. On a more personal note, the team process was empowering for both the scientific team members and the participating evacuees. The teams formed a cohesive group and a core subgroup of members continues to meet periodically, more to stay connected than to work on team activities. The experience of all of the members, including expert consultants, was overwhelmingly positive.

One of the teams' most memorable contributions was the design of a special commemorative pin to honor the experiences of the WTC survivors. The pins were produced and distributed initially at the community conference and later through the World Trade Center Survivors' Network. ${ }^{24}$ The pin was a fitting symbol of the team's efforts to improve high-rise safety and further helped to provide closure to a life-altering experience.

In conclusion, the PAR framework provided an efficient and effective mechanism for focusing the collective efforts of motivated individuals on disaster preparedness and response improvements; this approach may prove equally beneficial in other postdisaster studies.

\section{About the Authors}

Dr Gershon, Ms Rubin, and Ms Canton are with the Department of Sociomedical Sciences, Columbia University Mailman School of Public Health. Dr Qureshi is with the School of Nursing and Dental Hygiene, University of Hawaii at Manoa. Dr Matzner is with Our Lady of Mercy Medical Center.

Address correspondence and reprint requests to Dr Robyn R.M. Gershon, Department of Sociomedical Sciences, Columbia University Mailman School of Public Health, 722 W 168th St, Suite 1004, New York, NY 10032 (e-mail: rg405@columbia.edu).

This study was funded by the Centers for Disease Control and Prevention through a cooperative agreement with the Association of the Schools of Public Health (S2133-22/23, RRMG).

Received for publication March 21, 2008; accepted June 23, 2008.

\section{Authors' Disclosures}

The authors report no conflicts of interest.

\section{Acknowledgments}

The authors would like to thank Michael Hurley for advice on the study and the manuscript. The contribution of participatory action research team members Evelyn Alpert, Thomas Canavan, Jennell Francis, David S. Kelly, Peter Miller, John Pelletier, Edward Schmitt, and Frederick M. Zauderer is gratefully acknowledged. 
ISSN: $1935-7893$ C 2008 by the American Medical Association and Lippincott Williams \& Wilkins.

DOI: 10.1097/DMP.0b013e318184b48f

\section{REFERENCES}

1. Gershon RRM, Qureshi KA, Rubin MS, et al. Factors associated with high-rise evacuation: qualitative results from the World Trade Center evacuation study. Prehosp Disaster Med. 2007;22:165-173.

2. Fleischman AR, Wood EB. Ethical issues in research involving victims of terror. J Urban Health. 2002;79:315-321.

3. Qureshi KA, Gershon RRM, Smailes E, et al. Roadmap for the protection of disaster research participants: findings from the World Trade Center evacuation study. Prehosp Disaster Med. 2007;22:486-493.

4. Dickens L, Watkins K. Action research: rethinking Lewin. Manage Learn. 1999;30:127-140.

5. Lewin K. Resolving Social Conflicts, Selected Papers on Group Dynamics (1935-1946). New York: Harper \& Row; 1948.

6. Israel BA, Parker EA, Rowe Z, et al. Community-based participatory research: lessons learned from the centers for children's environmental health and disease prevention research. Environ Health Perspect. 2005; 113:1463-1471.

7. Whyte W, Greenwood D, Lazes P. Participatory action research: through practice to science in social research. Am Behav Sci. 1989;32: $513-551$.

8. Greenwood D, Whyte W, Harkavy I. Participatory action research as a process and as a goal. Hum Relat. 1993;46:175-192.

9. Israel BA, Schulz AJ, Parker EA, et al. Review of community-based research: assessing partnership approaches to improve public health. Annu Rev Public Health. 1998;19:173-202.

10. Israel B, House J, Schurman SJ, et al. The relation of personal resources, participation, influence, interpersonal relationships, and coping strategies to occupational stress, job strains, and health: a multivariate analysis. Work Stress. 1989;3:163-194.

11. Israel BA, Schurman SJ, House JS. Action research on occupational stress: involving workers as researchers. Int J Health Serv. 1989;19:135155.

12. Israel B, Schurman S, Hugentobler MK. Conducting action research: relationships between organization members and researchers. J Appl Behav Sci. 1992;28:74-101.

13. Baker EA, Israel BA, Schurman SJ. A participatory approach to worksite health promotion. J Ambul Care Manage. 1994;17:68-81.

14. Hugentobler MK, Israel BA, Schurman SJ. An action research approach to workplace health: integrating methods. Health Educ Q. 1992;19:55-76.

15. Schurman SJ. Making the "new American workplace" safe and healthy: a joint labor-management-researcher approach. Am J Ind Med. 1996;29: 373-377.

16. Broothroyd R. The impact of research participation on adults with severe mental illness. Ment Health Serv Res. 2000;2:213-221.

17. Newman E, Walker E, Gefland A. Assessing the ethical costs and benefits of trauma-focused research. Gen Hosp Psychiatry. 1999;21:187196.

18. Richards HM, Schwards LJ. Ethics of qualitative research: are there special issues for health services research? Fam Pract. 2002;19:135-139.

19. Newman E, Kaloupek DG. The risks and benefits of participating in trauma-focused research studies. J Trauma Stress. 2004;17:383-394.

20. World Trade Center (WTC) Health Registry. New York City Department of Health and Mental Hygiene Web site. http://www.nyc.gow/html/ doh/html/wtc/index.html. Accessed Jan 28, 2008.

21. Scholtes PR, Joiner BL, Streibel BJ. The Team Handbook. Madison, WI: Joiner/Oriel; 2003.

22. Office Building Emergency Action Plans. NYC Fire Department Web site. http://www.nyc.gov/html/fdny/html//rcny_legal//rcny_3rcny_sect_6_02.shtml. Accessed February 19, 2008.

23. Training Courses for Fire Safety/Emergency Action Plan Directors. http:// www.nyc.gov $/ \mathrm{htm} / \mathrm{fdny} / \mathrm{html} / \mathrm{rcny}$ _egal/rcny_3rcny_sect_9_08.shtml.Accessed February 19, 2008.

24. The World Trade Center Survivors' Network. http://www.survivorsnet.org. Accessed March 17, 2008. 